\title{
Cancer cell death induced by ferritins and the peculiar role of their labile iron pool
}

\author{
Juan Carlos Cutrin ${ }^{1}$, Diego Alberti ${ }^{1}$, Caterina Bernacchioni ${ }^{2}$, Silvia Ciambellotti ${ }^{2}$, \\ Paola Turano ${ }^{2}$, Claudio Luchinat ${ }^{2}$, Simonetta Geninatti Crich $^{1}$ and Silvio Aime ${ }^{2,3}$ \\ ${ }^{1}$ University of Torino, Department of Molecular Biotechnology and Health Sciences, Torino, Italy \\ ${ }^{2}$ Center for Magnetic Resonance, University of Florence, Florence, Italy \\ ${ }^{3}$ IBB-CNR, Sede Secondaria c/o MBC, Torino, Italy \\ Correspondence to: Simonetta Geninatti Crich, email: simonetta.geninatti@unito.it \\ Claudio Luchinat, email: Iuchinat@cerm.unifi.it
}

Keywords: ferritin; iron release; cancer therapy; HeLa cells; TFR 1

Received: May 04, $2017 \quad$ Accepted: April 28, $2018 \quad$ Published: June 15, 2018

Copyright: Cutrin et al. This is an open-access article distributed under the terms of the Creative Commons Attribution License 3.0 (CC BY 3.0), which permits unrestricted use, distribution, and reproduction in any medium, provided the original author and source are credited.

\section{ABSTRACT}

\begin{abstract}
Cellular uptake of human H-ferritin loaded with $\mathbf{5 0}$ or $\mathbf{3 5 0}$ iron ions results in significant cytotoxicity on HeLa cells at submicromolar concentrations. Conversely, Horse Spleen Ferritin, that can be considered a model of L-cages, as it contains only about $10 \%$ of $\mathrm{H}$ subunits, even when loaded with 1000 iron ions, is toxic only at $>1$ order of magnitude higher protein concentrations. We propose here that the different cytotoxicity of the two ferritin cages originates from the presence in H-ferritin of a pool of non-biomineralized iron ions bound at the ferroxidase catalytic sites of $\mathrm{H}$-ferritin subunits. This iron pool is readily released during the endosomal-mediated H-ferritin internalization.
\end{abstract}

\section{INTRODUCTION}

Ferritin is a protein highly conserved in living organisms, which stores iron as a bioavailable ferric-oxide mineral [1-3].

In animals, the 24-meric cage structure is assembled from two subunits, the heavy chain (H-chain) and light chain (L-chain), or a mix thereof. The two distinct subunits share a similar fold and $53 \%$ of sequence identity, but differ in their ability to handle iron. $\mathrm{H}$-subunits contain a catalytic center (ferroxidase or oxidoreductase site) where iron(II) is oxidized to iron(III) by dioxygen on the ms time scale [4]. L-subunits lack the ferroxidase site; iron oxidation in L-type cages occurs on a time scale of the order of minutes and the protein mainly provides a shell to maintain the ferric oxide biomineral in a soluble form [5].

The demineralized form of L-type ferritin (apoferritin) has been extensively used for drug cellular delivery. Encapsulation of doxorubicin [6], curcumin [7], cisplatin [8] and desferrioxamine B [9] are only few examples. The selective ability of cells to internalize
L- and H-cages through specific receptors has been demonstrated, namely SCARA5 (Scavenger receptor class A type 5) for L-rich cages and TfR1 (Transferrin receptor 1) for H-rich cages [10, 11].

Based on evidence attained from both epidemiological and molecular studies, new insights are linking the presence of excess iron and altered iron metabolism to cancer [12]. It is well established that many cancer cells reprogram iron metabolism in ways that result in net iron influx [13]. Iron starvation can impair cell development and growth, whereas excessive iron accumulation leads to cytotoxicity, resulting from an over-production of free radicals. Actually, it has been reported that certain types of tumor cells (principally those with c-myc and h-ras oncogenes expression) appear unable to deal properly with the excess iron, as a consequence of ferritin and ferroportin down-regulation $[14,15]$.

Herein we report our observations on cell death triggering, based on the delivery of iron to tumor cells, by the administration of iron-loaded ferritins. 


\section{RESULTS}

\section{Iron-loaded ferritins are toxic for HeLa cells}

To compare the effects of $\mathrm{H}$ - and L-ferritin on tumor cells, we sought a tumor cell model that expresses both TfR1 and SCARA5 receptors, such as the HeLa cells. This choice allowed us to compare the behavior of the two proteins in the same cell line.

In literature, a plethora of nanocarriers encapsulating different species within the natural horse spleen cage is available, as recently reviewed in [16]. This cage has the advantage of being commercially available and can be considered a model of L-cages, as it contains only about $10 \%$ of $\mathrm{H}$ subunits [17]. Horse spleen nanocages will be referred to as HoS-ferritin, hereafter. They have been studied in their apo form (HoS-apoferritin), in its commercially available form loaded with an average of 1000 iron ions/cage (HoS-1000), as determined by ICPMS, and in two forms with lower loading (namely HoS-50 and HoS-350) for comparison with $\mathrm{H}$-ferritin (see below).

Recently human H-ferritin has been proposed [6] as a potentially superior carrier for anticancer drug delivery because, given its human origin, it should not activate inflammatory or immunological response. Efficient heterologous expression methods for human $\mathrm{H}$-ferritin $(\geq 100 \mathrm{mg} / \mathrm{L}$ of purified protein, in our hands) $[4,18]$ make it attractive also from the economical point of view. As for HoS-ferritin, H-ferritin can also be loaded with variable amounts of iron. The first two iron ions/subunit (48 iron ions per cage) localize in the ferroxidase site; addition of more iron ions initiates the biomineralization reaction [4]. Here, we investigated two $\mathrm{H}$-ferritin cages differently loaded with iron, namely: i) one containing about 50 iron ions per cage (H-50, hereafter), which corresponds to the full saturation of the 24 ferroxidase sites; ii) the other, containing 350 iron ions per cage (H-350, hereafter), which corresponds to the full saturation of ferroxidase sites plus initial formation of the biomineral core as demonstrated in the TEM images (see Supplementary Figure 1). As expected the iron oxide core size, determined by TEM image analysis, was smaller in both $\mathrm{H}-350$ (3.3 \pm $0.7 \mathrm{~nm})$ and HoS-350 $(2.6 \pm 0.2 \mathrm{~nm})$ due to the lower iron content with respect HoS-1000 $(4.4 \pm 0.4 \mathrm{~nm})$, whereas HoS-50 and H-50 didn't show any measurable core.

The amount of iron internalized by HeLa cells upon $24 \mathrm{~h}$ incubation in media containing variable concentrations of $\mathrm{H}-$ and HoS-ferritin was obtained by ICP-MS determination of the intracellular iron content (Figure 1A). The relative amount of internalized iron when using H-350, HoS-350 and HoS-1000 roughly correlates with the iron loading of the two carriers. The amount of internalized iron after the treatment with $\mathrm{H}-50$ and HoS50 in the $1-8 \mu \mathrm{M}$ range was too low to be determined with sufficient accuracy; this finding is in line with what one could expect by scaling down the measured effect of
H-350 and HoS-350 by a factor of 7 in iron concentration. To demonstrate that the uptake of the H-Ferritins involves TfR1, a competition assay was carried out treating Hela cells with an excess of Holo-transferrin. After 5 hours of cell incubation in the presence of $\mathrm{H}-350$, the uptake of H-350 decreased by about $50 \pm 8 \%$ when the concentration of Holo-transferrin added to the culture medium was $20 \mu \mathrm{M}$ (Figure 1B). Since in the literature there are not competitors reported for SCARA5, the specific mediation of HoS-Ferritin uptake has been assessed by blocking experiments carried out with an anti-human SCARA5 antibody (anti-SCARA5 Ab, Figure 1C). The amount of iron internalized by cells treated with anti-SCARA5 Ab and incubated with HoS-1000 $0.5 \mu \mathrm{M}$ for $5 \mathrm{~h}$ was $56 \pm$ $21 \%$ than the amount internalized by control cells, thus confirming that SCARA5 mediates HoS-Ferritin uptake in Hela cells. Moreover, in order to assess whether the presence of $10 \%$ of $\mathrm{H}$-chains in horse spleen ferritin used in this study can mediate its uptake through H-Ferritin receptors, a further competition study was carried out by incubating Hela cells for 5 hours with HoS-1000 $(1 \mu \mathrm{M})$ in the presence of a 20-fold excess of Holo-transferrin. The Holo-transferrin excess caused a non significant reduction $(3 \pm 2 \%$ ) of internalized iron thus ruling out the involvement of TfR 1 receptors in the internalization of HoS-Ferritin (Figure 1D). The specificity of the ferritin targeting system was further confirmed by incubating H-350 and HoS-350 with an excess of H-Apo and HoSApo (Supplementary Information, Supplementary Figure $2)$. A significant decrease $(>50 \%)$ of the internalized iron was observed only in the presence of the corresponding H-Apo or HoS-Apo forms. Vice versa no effect has been detected incubating H-350 and HoS-350 with an excess of HoS-Apo and $\mathrm{H}-350$, respectively.

Cell viability was determined by the MTT assay after treatment of HeLa cells for $24 \mathrm{~h}$ with apo and ironloaded $\mathrm{H}-$ and HoS-ferritins. While both apo forms show no appreciable toxicity, a clear effect is induced by the iron-loaded cages (Figure 2A). Strikingly, the profiles of cellular cytotoxicity induced by the H- and L-cages are very different. The effect of HoS-1000 is almost linearly dependent on the protein concentration whereas the less loaded HoS-350 and HoS-50 showed a toxicity not significantly different from the apo form. On the contrary, treatment with either H-50 or H-350 causes an abrupt decrease in cellular viability, which levels off at about $50 \%$ viability for $\mathrm{H}-350$ concentrations $\geq 1 \mu \mathrm{M}$ ferritin. The attainment of a plateau value in cell viability for both ironloaded $\mathrm{H}$-ferritin nanocages can be interpreted in terms of iron-dependent downregulation of the TfR1 receptor expression; a well-known process in the case of incubation of HeLa with an excess of holo-transferrin or Fe-citrate $[19,20]$. A flow cytometric analysis of the expression of TfR1 (Supplementary Figure 3) showed that the relative expression of this receptor with respect to untreated Hela cells decreases to $58 \pm 5 \%$ for cells treated with $1 \mu \mathrm{M}$ 
$\mathrm{H}-350$ and to $75 \pm 6 \%$ with $1 \mu \mathrm{M} \mathrm{H}-50$, suggesting that also iron-loaded $\mathrm{H}$-ferritins activate a downregulation mechanism. From the results shown in Figure 2A (lack of saturation effects in cytotoxicity when using HoS-1000), one may rule out the occurrence of an analogous irondependent SCARA5 down regulation response. In spite of the larger intracellular iron internalization induced by HoS-1000 with respect to $\mathrm{H}-350$ or $\mathrm{H}-50$, the latter two are much more toxic at lower protein concentrations. As illustrated in Figure 2B, for a given iron concentration, $\mathrm{H}-350$ causes significantly larger reduction in cell viability, suggesting a different mechanism of action for H- and L-cages. Noteworthy, the comparison in the cytotoxic effect exerted by treatment with H-50 and H-350 is not proportional to their cage iron content. This result suggests that the nature of the iron ions within the cage (ferroxidase-bound or biomineralized) might play a role. In principle, one may surmise that ferroxidase-bound iron could be associated to the generation of toxic ROS. This aspect is further investigated in the following sections.

Cytoplasmic ROS production was evaluated by measuring 2,7-dichlorofluorescein diacetate (DCF-DA) emission; its fluorescence intensity directly correlates with the steady-state concentration of intracellular ROS. The treatment with $5 \mu \mathrm{M}$ iron-loaded ferritins causes a modest increase in ROS production with respect to untreated cells and to cells treated with the apoferritins (Figure 2C). ROS generation by $\mathrm{H}-350$ is only modestly higher than that of $\mathrm{H}$-apo, while $\mathrm{H}-50$ is indistinguishable from the other two, within the error. HoS-1000 induces a ROS production which is significantly higher than HoSApo, but still less than a factor of 2 whereas HoS-350 and HoS-50 are not significantly different. In conclusion, cytoplasmatic ROS production does not account for the striking differences in cell viability between $\mathrm{H}$ and $\mathrm{L}$ of Figure 2A. Consistently, at protein concentrations lower than $5 \mu \mathrm{M}$, where the $\mathrm{H}-350$ and $\mathrm{H}-50$ are heavily toxic (Figure 2A), no measurable ROS production is observed.

Moreover, in order to discriminate between an antiproliferative or toxic- effect of ferritins, Hela cells have been incubated in the presence of $\mathrm{H}-50(0.5 \mu \mathrm{M})$ or $\mathrm{H}-350(0.5 \mu \mathrm{M})$ or $\mathrm{L}-1000(3 \mu \mathrm{M})$. This treatment caused the death of about $30-40 \%$ of cells. Then the proliferation rates of the survived cells have been assessed over a period of 5 days. No significant difference has been noted between these cells and the untreated control cells (see
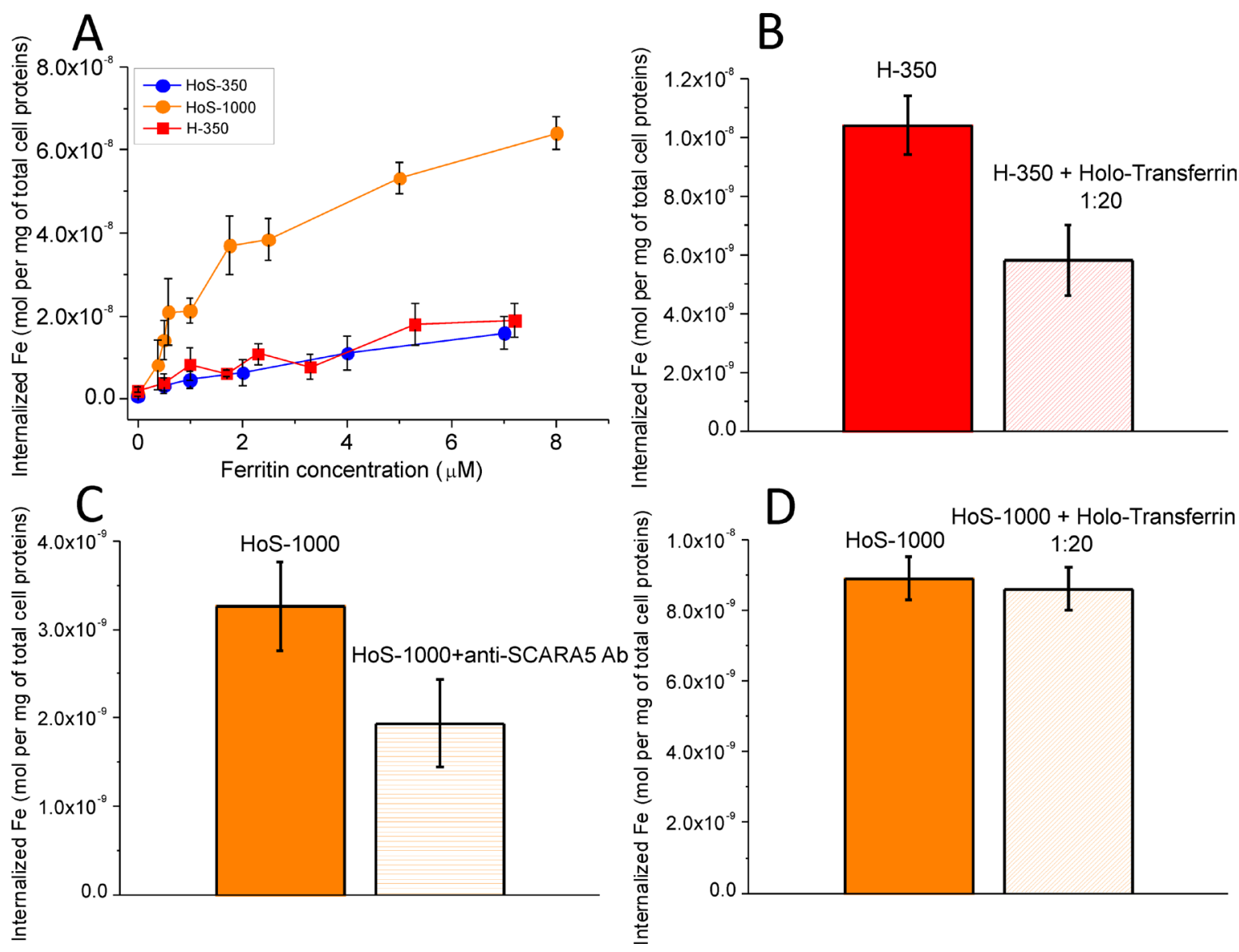

Figure 1: In cell studies: iron cell uptake. (A) After $24 \mathrm{~h}$ incubation in the presence of increasing amounts of different ferritins, cell lysates were analyzed by ICP-MS to measure the amount of internalized iron, which was normalized to the total protein cellular content; (B, C, D) competition studies: iron uptake by Hela cells after $5 \mathrm{~h}$ incubation in the presence of (B) H-350 (1 $\mu \mathrm{M})$ and HoS-1000 (D) with and without the addition of an excess of holo-transferrin $(20 \mu \mathrm{M})$; (C) HoS-1000 $0.5 \mu \mathrm{M}$ with and without anti-SCARA5 antibody $5 \mathrm{mg} / \mathrm{ml}$. 
Supplementary Figure 4). This finding led us to exclude that the reduced metabolism measured with the MTT assay is related to the occurrence of a reduced proliferation rate.

\section{The role of $\mathrm{pH}$ and endogenous reducing agents on iron release}

As reported [10], TfR1-imported H-ferritin is initially localized in endosomes and then (in about 30 min) is distributed in both endosome and lysosomes. The cytotoxic effect of H-350 in the MTT assay carried out in the presence of chloroquine (CHL), an agent that limits endosomal acidification, resulted significantly reduced ( $P=0.0076$; Figure $3 \mathrm{~A})$. The effect is much smaller in the presence of DFO mesylate, a lysosomal iron chelator. The opposite behavior is observed for HoS-1000 (Figure 3A). Degradation of HoS-cages encapsulating massive biomineral particles (1000 iron/ cage) gives rise to observable hemosiderin bodies [21] (Figure 3B). Accordingly, confocal microscopy studies (see Supplementary Figure 5) showed that HoS-ferritin was completely compartmentalized in lysosomes, whereas H-ferritin is only in part inside the lysosomal compartment. Using TfR1, H-ferritin was internalized by the receptor-mediated mechanism, only in part undergoing lysosomal degradation. Despite the much lower amount of delivered iron, H-ferritin appears definitively more toxic.

Mature endosomes are characterized by a low $\mathrm{pH}$ value $(4.9-6.0)$ [22, 23]. At $\mathrm{pH} 5$, only $\mathrm{H}$-ferritin spontaneously releases iron(II), whereas at neutral $\mathrm{pH}$ the presence of reducing agents is required (Figure 4A). HoS-1000 is able to release iron(II) only in the presence of reducing agents (Figure 4B). The amounts of iron(II) released by $\mathrm{H}-50$ and $\mathrm{H}-350$ account for a total of 21
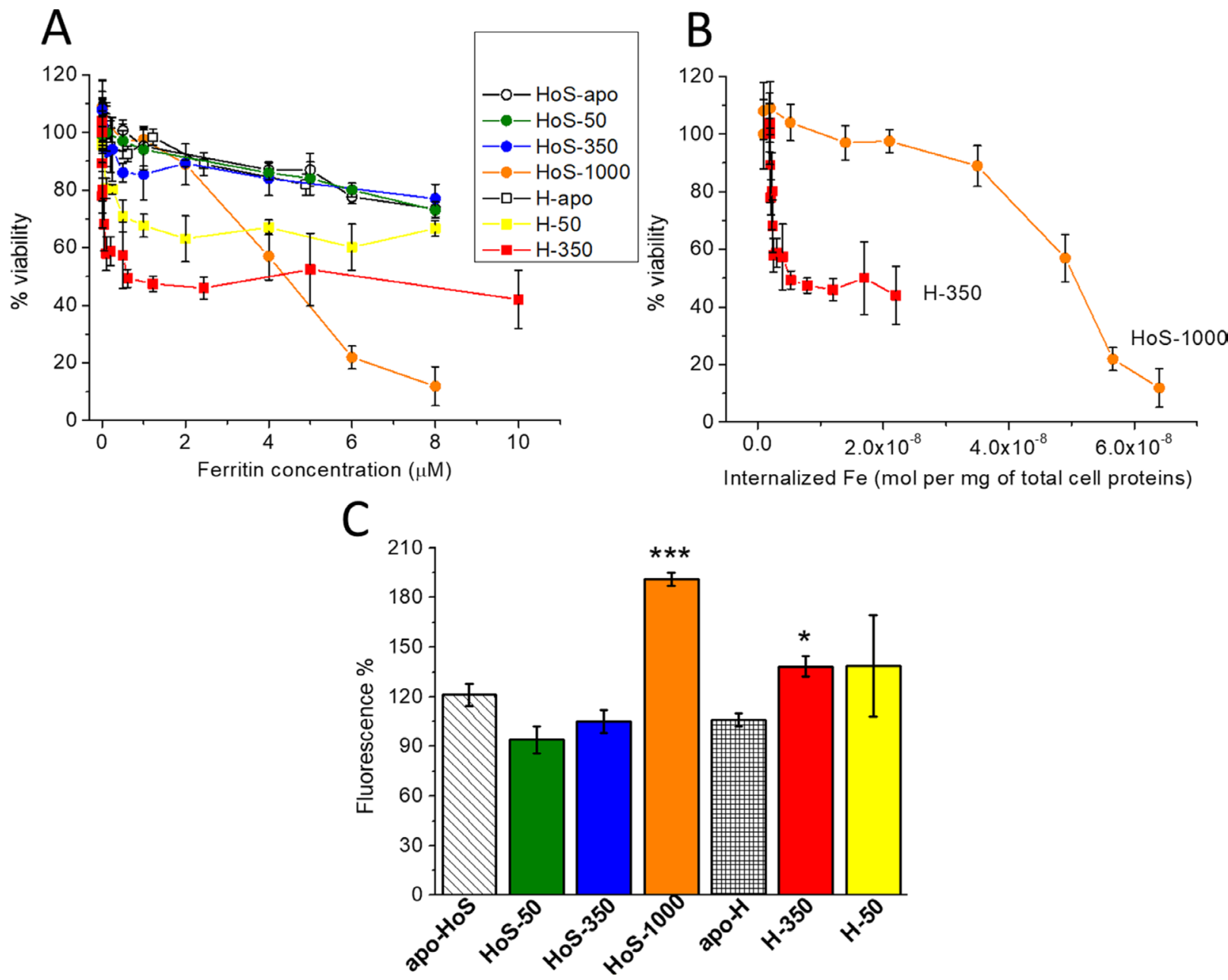

Figure 2: In cell studies: iron toxicity. (A, B) HeLa cell viability measured by the MTT assay as a function of the concentration of the various ferritin forms (A) and as a function of internalized iron (B). Cell viability is expressed as percentage relative to untreated cells. Data are presented as mean and SD of at least three independent experiments. (C) ROS generation measured by DCF-DA fluorescence emission (at $529 \mathrm{~nm}$ ) after the incubation, for $24 \mathrm{~h}$, of HeLa cells with $5 \mu \mathrm{M}$ different form ferritins. In all panels, error bars indicate the SD of the data. (Student's $t$ test. HoS-1000 vs HoS-Apo: $P=0.0002$; H-350 vs apo-H: $P=0.03$; H-50 vs apo-H: $P=0.24 ;{ }^{*} P<0.05$, ${ }^{* * *} P<0.001$ ). In panels $\mathrm{A}, \mathrm{B}$ and $\mathrm{C}, \mathrm{HoS}$-apoferritin $(\mathrm{HoS}-\mathrm{Apo})$ and $\mathrm{H}$-apoferritin $(\mathrm{H}-\mathrm{Apo})$ are represented as white circles and squares, respectively; HoS-1000 as orange circles, HoS-350 as blue circles, HoS-50 as green circles, H-350 as red squares and H-50 as yellow squares. In panel $\mathrm{D}$, the bars are labelled and depicted with the same color code used in A, B and C. 
iron/cage and 57 iron/cage, respectively. The observed $\mathrm{pH}$ dependence of iron release in vitro suggests that in cells $\mathrm{H}$-ferritin can release its metal load at the level of late endosomes, but HoS-1000 does not. In lysosomes, $\mathrm{pH}$ drops down to about 4.5; the harsher conditions combined with the possible degradation operated by lysosomal hydrolases [23] may cause cage disassembly.
Moreover, iron(III) release has been determined using the orange xylenol based assay [24]. Xylenol orange has long been known as a good chelator for the quantitative determination of a wide range of cations, including iron. It binds $\mathrm{Fe}^{3+}$, but not $\mathrm{Fe}^{2+}$, at acid $\mathrm{pH}$ to give a colored complex [24] and the reaction is not sensitive to oxygen. Figure 4C and 4D show that HoS-1000 releases iron(III)
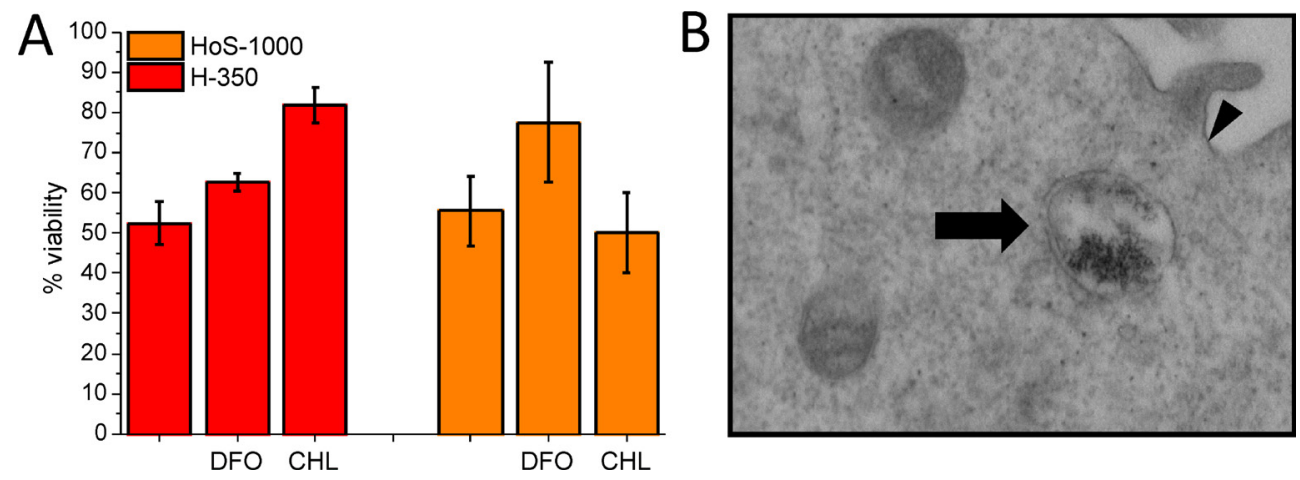

Figure 3: Iron release along the endosome/lysosome import system. (A) HeLa cell viability measured by the MTT assay after 24 of incubation with H-350 $(0.5 \mu \mathrm{M})$ or HoS-1000 $(2.5 \mu \mathrm{M})$ in the absence and in the presence of DFO mesylate $(150 \mu \mathrm{M})$ and Chloroquine $(100 \mu \mathrm{M}){ }^{* *} P<0.01$, Student's $t$-test). (B). TEM pictures of Hela cells treated with HoS-1000. Arrows indicate representative endosomes. Hemosiderin bodies are observed only upon incubation with HoS-ferritin. The arrowhead signs correspond to the plasma membrane $(\times 30.000$, lead citrate and uranyl acetate stained $)$.
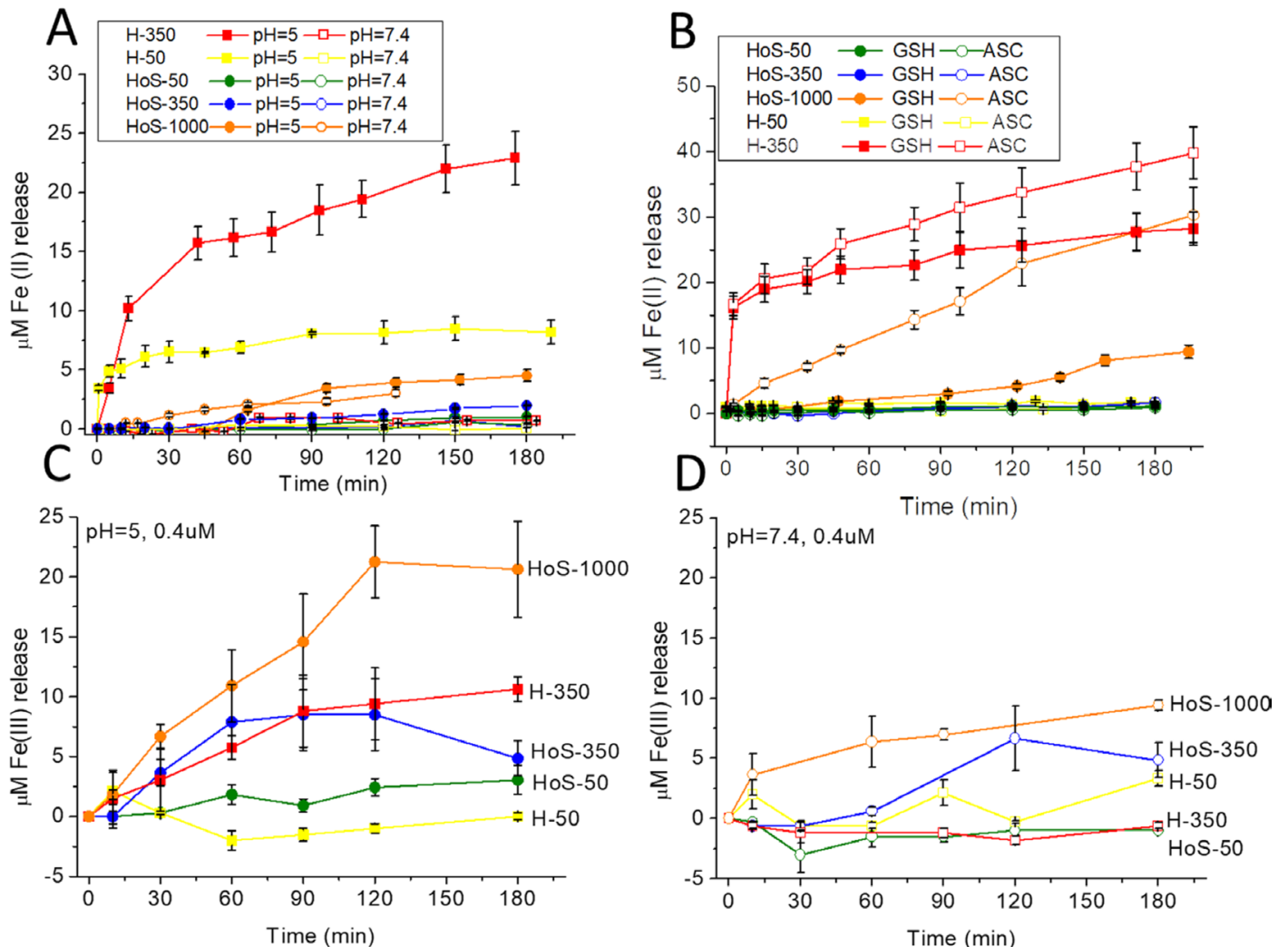

Figure 4: (A, B) Mobilization of iron(II) from $0.4 \mu \mathrm{M}$ H-50, H-350, HoS-50. HoS-350 and HoS-1000 as a function of pH (A) and (B) in the presence of reducing agents (GSH $0.25 \mathrm{mM}, \mathrm{pH}=7$; ascorbic acid $0.25 \mathrm{mM}, \mathrm{pH}=7$ ). Samples were incubated with bipyridine $(1 \mathrm{mM})$ under aerobic conditions. The amounts of iron(II) released by H-50 and H-350 account for a total of 21 iron/cage and 57 iron/ cage, respectively. (C, D) Mobilization of iron(III) from $0.4 \mu \mathrm{M} \mathrm{H}-50, \mathrm{H}-350$, HoS-50. HoS-350 and HoS-1000 at $\mathrm{pH}=5(\mathrm{C})$ and $\mathrm{pH}=$ 7.4 (D). Samples were incubated with Xylenol Orange $(0.25 \mathrm{mM})$ under aerobic conditions. $\mathrm{T}=0$ corresponds to the addition of ferritin to the solution media. 
at neutral and, in particular, at acid $\mathrm{pH}$ more than $\mathrm{H}-350$ and H-50, whereas the iron(III) released from HoS-350 at acid $\mathrm{pH}$ is similar to $\mathrm{H}-350$. While iron(III) release in the presence of xylenol orange seems to be proportional to the biomineral content, independently of the cage type, the release of iron(II) in the presence of 2,2'-bipyridine is selectively observed for H-ferritin. Organisms and cells keep this ferric iron in solution by secreting chelating agents able to bind $\mathrm{Fe}(\mathrm{III})$ more tightly than $\mathrm{OH}-$ and thus preventing the oxo-bridging of Fe(III) species that leads to its precipitation [25]. However, by stabilizing this $\mathrm{Fe}(\mathrm{III})$ state, the chelating agents set the Fe(III) reduction potential at a low value that prevents its participation as oxidant in reaction with a biologic reducing agent. This 'stable' ferric iron is inert in regard to the Fe(III) reduction reaction associated with normal iron metabolism.

\section{Relaxometric characterization}

Horse spleen ferritin has been proposed as a carrier for MRI contrast agents [26, 27]; here, we investigate the relaxometric properties of ferritins with different iron loadings. 1/ $\mathrm{T}_{1}$ NMRD profiles (Figure 5A) were recorded for H-50, H-350, HoS-50, HoS-350 and HoS-1000. The profiles are only marginally affected by addition of deferoxamine (DFO) that it is expected to bind only the iron fraction possibly present on the external surface of the protein (Figure 5B). The profiles indicate a negligible contribution from externally coordinated iron ions. The higher millimolar relaxivities at any field shown by $\mathrm{H}-50$ and, to a lower extent by HoS-50, suggest a paramagnetic contribution from nonbiomineralized iron (Figure 5). This contribution is less pronounced in H-350 and almost absent in HoS-1000. As reported [28], the differences in $\mathrm{H} / \mathrm{L}$ ratio in ferritin cages determine different morphologies of the mineral core and this fact might influence the relaxivity profiles.

\section{DISCUSSION}

\section{A structural biology view of different toxicity of $H$ and $L$ chains}

Recent X-ray crystallography studies have demonstrated that the ferroxidase site of human $\mathrm{H}$-ferritin accommodates two iron ions, named Fe1 and Fe2, that are bound to few protein amino acid side chains: a bridging carboxylate group is provided by Glu62; Fe1 is then bound to His 65 and monodentate Glu27; Fe2 to bidentate Glu107; the coordination sphere of each iron ion is completed by water molecules. Nearby, there are two other additional binding sites involving the side chains of His57, Glu58 and Glu62, where hydrated iron ions are bound with low occupancy. The emerging picture is that of a cage that uptakes ferrous hexa-aqua ions through the C3 channels and delivers them (as progressively de-hydrated ions) towards the ferroxidase site under the effect of attractive electrostatic gradient created by carboxylate residues $[29,30]$. Given the low number of protein residues involved in the binding of the iron at the accessory binding sites and in the ferroxidase site, it is reasonable to propose that they could be more readily released and react. The Fe1 and Fe 2 sites remain always populated during subsequent reaction turnover, while the biomineral grows. Their iron release upon lowering $\mathrm{pH}$ can be explained in terms of protonation of the acidic residues involved in their binding. In contrast, in human L-ferritin and horse spleen ferritin, some of us have demonstrated that the iron ions that enter the $\mathrm{C} 3$ channels and react to form the biomineral precursors at the nucleation sites are blocked within $\left(\mu^{3}\right.$-oxo)tris $\left[\left(\mu^{2}\right.\right.$-peroxo $)\left(\mu^{2}\right.$-glutamato- $\left.\left.\kappa: \kappa O^{\prime}\right)\right]$ (glutamato- $\kappa O)($ diaquo)triiron(III) clusters. So they are probably more stable than iron ions in the ferroxidase site and lose their importance when the biomineral grows

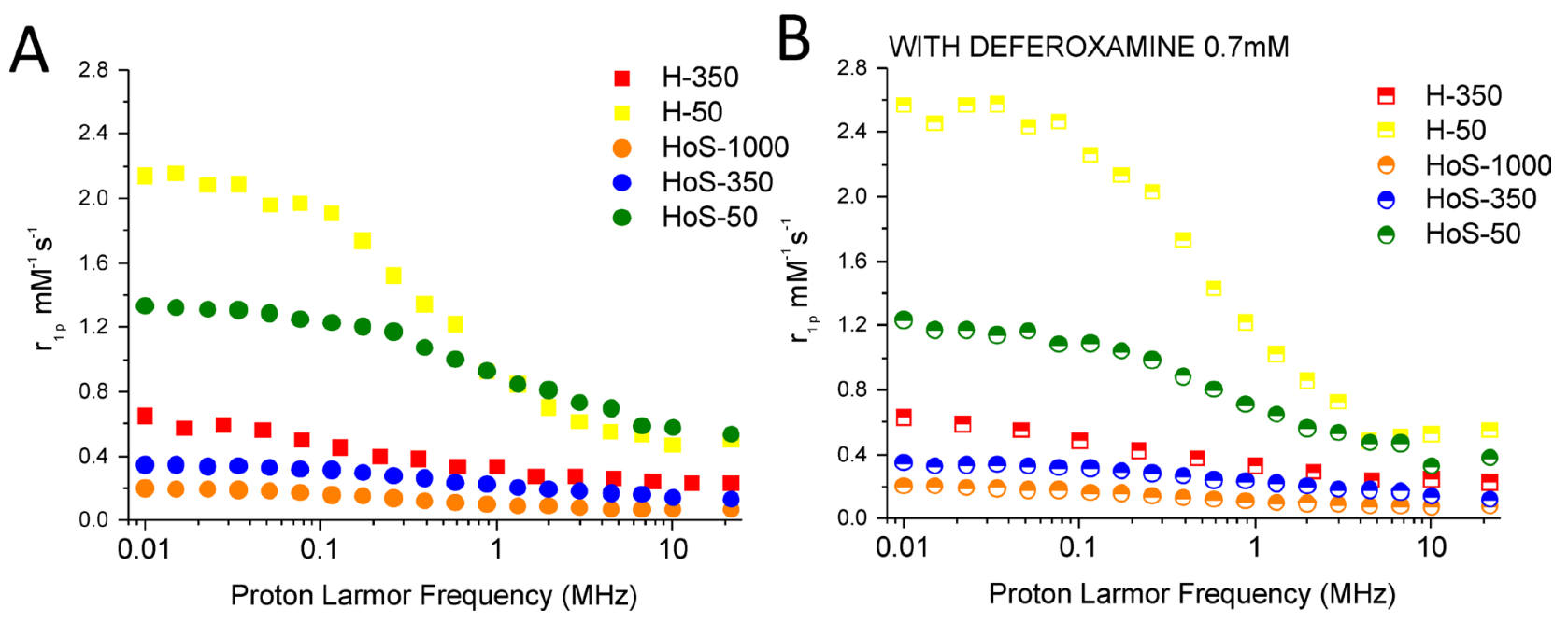

Figure 5: Ferritins as relaxation agents. $1 / \mathrm{T}_{1} \mathrm{NMRD}$ profiles $\left(\mathrm{pH} 7.4,25^{\circ} \mathrm{C}\right)$ of $\mathrm{H}-50, \mathrm{H}-350, \mathrm{HoS}-50, \mathrm{HoS}-350$ and $\mathrm{HoS}-1000$ $\left(10 \mu \mathrm{M}\right.$ in protein). The profiles were recorded without (A) and with the ferritins treatment with DFO $0.7 \mathrm{mM}\left(15^{\prime}\right.$ at $\left.25^{\circ} \mathrm{C}\right)(\mathbf{B})$, to avoid any possible contribution from spurious surface iron ions. The relaxivity values $\left(\mathrm{r}_{1 \mathrm{p}} \mathrm{mM}^{-1} \mathrm{~s}^{-1}\right)$ were normalized to the iron concentration. 
[31]. Furthermore, we can hypothesize an additional toxic effect due to the direct reaction of $\mathrm{H}_{2} \mathrm{O}_{2}$ generating $\mathrm{OH}$ inside the protein cavity. In fact, as reported by Zhao and coworkers [32], $\mathrm{H}_{2} \mathrm{O}_{2}$ is able to react with the ferroxidasebound iron(III), showing a stronger reactivity with the $\mu$-oxo diferric complex than with the Fe(III) core which is more thermodynamically stable (in particular in the case of L-ferritin). The reactivity is inversely proportional to the size of the $\mathrm{Fe}(\mathrm{III})$ core.

\section{Therefore, the higher H-ferritin toxicity originates from its peculiar iron cargo as well by its pathway of interaction with the ELC}

The characteristic behavior observed for H-ferritin, which shows toxicity effects that are not proportional to the iron-load, suggests a different behavior for the biomineralized caged iron and the "mobile" iron pool constituted by those metal ions that are at the relatively weakly binding ferroxidase sites and low-populated accessory binding sites in the catalytic center [4, 29, 33]. Indeed, the observed effects can be accounted for as originating by a pool of about 50 iron/cage over a total of 350/cage. Moreover the reduced acidification capacity of the ELC obtained by the treatment with CHL significantly reduces the $\mathrm{H}$ - but not $\mathrm{HoS}$-ferritin induced cytotoxicity (Figure 3A). This divergent effect could be explained by the $\mathrm{pH}$-dependent $\mathrm{H}$-ferritin release of iron at the level of late endosomes, i.e. the neutralization of endosomal $\mathrm{pH}$ induced by $\mathrm{CHL}$ increases the iron retention by $\mathrm{H}$-ferritin. The not-yet biomineralized iron could be released more easily upon acidification (Figure 4A) from the protein sites in the ferroxidase site, where the coordination sites are mainly provided by carboxylate and imidazole side chains. The redox activity, as measured by cytoplasmatic ROS generation, is only modestly increased from the apo- to the iron-loaded proteins and the increase is actually more modest for $\mathrm{H}$ than for $\mathrm{L}$. We conclude that iron toxicity is only marginally dependent on ROS generation.

\section{The apparent $H$ paradox}

Our present findings rise an obvious question. Why a human protein is toxic for human cells? Here we have to consider a few key aspects: i) Endogenous ferritin is a cytoplasmic protein; under the cytosolic $\mathrm{pH}$ its cargo is stable and is not readily released [34]. ii) The natural cytoplasmic ferritin never undergoes endosomal-mediated import with consequent iron release induced by the low $\mathrm{pH}$ in endosome. iii) Only ferritin that could be externally administered via the blood stream can be internalized via TfR-1 receptors leading to endosomal internalization.

The expression of TfR 1 on tumor cells is accounted for in terms of the needs for the fast growing tumor cells to import sufficient iron for the set-up of fundamental biological functions. However, when $\mathrm{H}$-ferritin is involved in place of transferrin, the iron uptake may overcome the physiological needs and the toxic role of redox iron center come to prevail. The observed behavior may be accounted for in terms of the set-up of a spontaneous cell death process induced by iron-loaded $\mathrm{H}$-ferritin taken up through TfR1 receptors.

In summary, the toxicity of iron-loaded H-ferritin is due to two main factors: the presence of a mobile iron pool, which has no counterpart in HoS-ferritins, and the lability of this pool at the low $\mathrm{pH}$ encountered during the endosomal import. On this basis, the exploitation of $\mathrm{H}$-ferritins pro-toxic properties may open new horizons in the field of novel cancer therapies based on an iron dependent-mechanism that leads to cell death.

\section{MATERIALS AND METHODS}

Apoferritin and iron-loaded ferritin from equine spleen (reported to contain $>90 \%$ of L subunits), Thiazolyl Blue Tetrazolium Bromide, DCF-DA, deferoxamine mesylate, chloroquine and all other chemicals were purchased from Sigma-Aldrich (St Louis, MO). The apo- and iron-loaded ferritin samples were used without any further purification and, given their composition, are hereafter named HoS-Apo and HoS-1000. The number of Fe/cage in iron-loaded HoS-ferritin was measured by ICP-MS.

\section{H-ferritin production/purification}

The gene-coding sequence for human H-ferritin was custom-synthesized (GenScript, USA) and subcloned into pET-9a expression vector using NdeI and BamHI restriction sites. The expression plasmid was introduced by thermal shock into E. coli strain BL21 (DE3) pLysS cells. Transformants were selected in LB agar supplemented with $50 \mathrm{mg} \mathrm{L}^{-1}$ kanamycin. Cells were grown at $37^{\circ} \mathrm{C}$ until $\mathrm{A}_{600 \mathrm{~nm}}$ reached $0.6-0.8$, and subsequently induced with isopropyl 1 -thio- $\beta$-D-galactopyranoside (IPTG, 1 $\mathrm{mM}$ final concentration) for $4 \mathrm{~h}$. Human $\mathrm{H}$-ferritin was purified from the harvested cells, as described previously $[4,18]$. Briefly, cells were broken by sonication and the cell free extract obtained after centrifugation (40 min, $40,000 \mathrm{rpm}, 4^{\circ} \mathrm{C}$ ) was incubated for $15 \mathrm{~min}$ at $65^{\circ} \mathrm{C}$ as the first purification step. After removal of the aggregated proteins $\left(15 \mathrm{~min}, 40,000 \mathrm{rpm}, 4^{\circ} \mathrm{C}\right)$, the supernatant solution was dialyzed against $20 \mathrm{mM}$ Tris- $\mathrm{HCl} \mathrm{pH} 7.5$; applied to a Q-Sepharose column in the same buffer and eluted with a linear $0-1 \mathrm{M} \mathrm{NaCl}$ gradient in $20 \mathrm{mM}$ Tris$\mathrm{HCl} \mathrm{pH}$ 7.5. Fractions containing ferritin, identified by Coomassie staining of SDS-PAGE gels, were combined and further purified by size exclusion chromatography using a Superdex 200 16/60 column. (GE Healthcare Life Sciences) Iron and other metal ions present in the purified ferritin were removed by four dialysis steps overday and at $4^{\circ} \mathrm{C}$ overnight, each using $4 \mathrm{~L} 20 \mathrm{mM}$ Tris- $\mathrm{HCl}, 2.5 \mathrm{mM}$ 
EDTA, $10 \mathrm{~mL}$ ammonium thioglycolate $\mathrm{pH} 7.5$ to reduce and chelate the iron, followed by four dialysis steps at room temperature each using $4 \mathrm{~L} 20 \mathrm{mM}$ Tris-HCl, $\mathrm{pH}$ 7.5.

\section{Preparation of iron-loaded $\mathrm{H}$-ferritin and $\mathrm{HoS}_{-}$ ferritin}

Iron loading into human recombinant $\mathrm{H}$-apoferritin homopolymer $(100 \% \mathrm{H}$ chain) and HoS-Apo from equine spleen was carried out by adding a $\mathrm{FeSO}_{4}$ solution (200 $\mathrm{mM}$ in $1 \mathrm{mM} \mathrm{HCl}$ at protein/Fe ratio of $1: 500$ and 30 $\mathrm{mM}$ in $1 \mathrm{mM} \mathrm{HCl}$ at protein/ $\mathrm{Fe}$ ratio of $1: 75$ ) to a 4.5 $\mu \mathrm{M}$ protein solution dissolved in $100 \mathrm{mM}$ MOPS, 100 $\mathrm{mM} \mathrm{NaCl} \mathrm{pH} 7$ buffer. After the addition of the iron salt, the sample was vigorously vortexed for $5 \mathrm{sec}$, then left at $25^{\circ} \mathrm{C}$ for 2 hours and at $4^{\circ} \mathrm{C}$ overnight. The ironloaded $\mathrm{H}$-ferritin and $\mathrm{HoS}-$ ferritin were then purified by two cycle of dialysis at $4^{\circ} \mathrm{C}$ using $1 \mathrm{~L}$ of $4 \mathrm{mM}$ Hepes, $150 \mathrm{mM} \mathrm{NaCl}$ pH 7.4 as external buffer. Final iron concentration was measured by ICP-MS. Samples of $\mathrm{H}$-ferritin and $\mathrm{HoS}-$ ferritin were loaded with about $350(\mathrm{H}-350$ and $\mathrm{HoS}-350)$ and $50(\mathrm{H}-50$ and $\mathrm{HoS}-50)$

$\mathrm{Fe} /$ cage. The protein concentration was measured by the Bradford assay using Bovine Serum Albumin (BSA) as a standard.

\section{ICP-MS}

Iron concentration was determined by using inductively coupled plasma mass spectrometry (ICP-MS; element-2; Thermo-Finnigan, Rodano (MI), Italy). Sample digestion was performed with concentrated $\mathrm{HNO}_{3}(70 \%$, $1 \mathrm{~mL}$ ) under microwave heating at $160^{\circ} \mathrm{C}$ for 8 minutes (Milestone MicroSYNTH Microwave labstation).

\section{NMRD profiles}

The $1 / T_{1}$ nuclear magnetic relaxation dispersion profiles (NMRD) of water protons were measured over a continuum of magnetic field strengths from 0.00024 to $0.5 \mathrm{~T}$ (corresponding to $0.01-20 \mathrm{MHz}$ proton Larmor frequency) on a Fast Field Cycling relaxometer (Stelar Spinmaster FFC 2000 relaxometer) equipped with a resistive low inductance air cored silver solenoid [35]. The relaxometer operates under complete computer control with an absolute uncertainty in the $1 / \mathrm{T}_{1}$ values of $\pm 1 \%$. The typical field sequences used were the NP sequence between 20 and $8 \mathrm{MHz}$ and the PP sequence between 8 and $0.01 \mathrm{MHz}$. The observation field was set at $16 \mathrm{MHz}$. $\mathrm{T}_{1}$ was determined by the saturation recovery method. 16 values of delay $(t)$ between pulses were used. The number of averaged experiments was 2 .

\section{HeLa cell line}

Cervical carcinoma (HeLa) cell line was obtained from the American Type Culture Corporation. They were cultured in RPMI 1640 medium (Lonza) containing $10 \%(\mathrm{v} / \mathrm{v})$ fetal bovine serum (FBS), $2 \mathrm{mM}$ glutamine, $100 \mathrm{U} / \mathrm{ml}$ penicillin, and $100 \mathrm{U} / \mathrm{ml}$ streptomycin. Cells were incubated at $37^{\circ} \mathrm{C}$ in a humidified atmosphere of $5 \% \mathrm{CO}_{2}$. The cell line was routinely tested to make sure of the absence of mycoplasma contamination (MycoAlert ${ }^{\mathrm{TM}}$ PLUS Mycoplasma Detection Kit, Lonza).

\section{Uptake experiments}

For uptake experiments, HeLa cells were seeded at a density of $2.5 \times 10^{5}$ cells in a $25 \mathrm{~cm}^{3}$ culture flask and placed in a wet $\left(37^{\circ} \mathrm{C}\right) 5 \% \mathrm{CO}_{2}$ air atmosphere incubator. At $24 \mathrm{~h}$ post seeding, cells were incubated with increasing concentrations of the above-mentioned $\mathrm{H}-350, \mathrm{HoS}-350$ or HoS-1000. After $24 \mathrm{~h}$ of incubation, cells were washed three times with $10 \mathrm{~mL}$ ice-cold PBS, detached with trypsin/EDTA and sonicated for 30 " at $30 \%$ power in ice. The Fe content was determined by ICP-MS. The protein concentration (proportional to the cell number) was determined from cell lysates by the Bradford assay, using BSA as a standard.

\section{Proliferation assay}

For proliferation assay, Hela cells were seeded at a density of $4 \times 10^{4}$ cells in a $3.5 \mathrm{~cm}$ diameter petri dishes and placed in a wet $\left(37^{\circ} \mathrm{C}\right) 5 \% \mathrm{CO}_{2}$ air atmosphere incubator. At $24 \mathrm{~h}$ post seeding, four dishes were incubated with $\mathrm{H}-50(0.5 \mu \mathrm{M})$ or $\mathrm{H}-350(0.5 \mu \mathrm{M})$ or $\mathrm{HoS}-1000(3 \mu \mathrm{M})$ for $24 \mathrm{~h}$. Untreated cells were used as a control. At the end of the incubation, they were washed three times with $10 \mathrm{~mL}$ ice-cold PBS and only a dish for each incubated ferritins, detached with trypsin/EDTA, sonicated and transferred into falcon tubes. Then, cells were sonicated and the protein concentration (proportional to the cell number) from cell lysates was determined by the Bradford method. The remaining dishes were leaved in cell incubator at $37^{\circ} \mathrm{C}$ and $5 \% \mathrm{CO}_{2}$ detached with trypsin/ EDTA at day 2,3 and 5 post incubation and their protein concentration was determined.

\section{Competition assays}

To demonstrate that the uptake of $\mathrm{H}-350$ involves TfR 1 and in order to assess whether the presence of $10 \%$ of H-chains in HoS-ferritin can mediate its uptake through H-Ferritin receptors competition assays was carried out. Hela cells were seeded at a density of $2.5 \times 10^{5}$ in a $6 \mathrm{~cm}$ diameter petri dishes and placed in a wet $\left(37^{\circ} \mathrm{C}\right) 5 \% \mathrm{CO}_{2}$ air atmosphere incubator. At $24 \mathrm{~h}$ post seeding, $\mathrm{H}-350$ $(1 \mu \mathrm{M})$ and $\mathrm{HoS}-1000(1 \mu \mathrm{M})$ were incubated in the presence of Holo transferrin human (Sigma) $20 \mu \mathrm{M}$ for 5 hours. Moreover, to demonstrate that the uptake of HoSFerritin involves SCARA5 receptors, 24 h post seeding, Hela cells were incubated with HoS-1000 $(0.5 \mu \mathrm{M})$ for $5 \mathrm{~h}$ in the presence of $5 \mu \mathrm{g} / \mathrm{mL}$ anti-SCARA5 antibody 
(abcam ab118894) blocking the receptor. The competitions were evaluated by measuring Fe content by ICP-MS of cell lysates with respect to $\mathrm{H}-350$ or $\mathrm{HoS}-1000$ incubated in the same condition without the presence of competitor.

\section{FACS analysis of Transferrin Receptor expression}

In order to perform FACS (Fluorescence Activated Cell Sorting) analysis, $2 \times 10^{5}$ Hela cells were seeded in $3.5 \mathrm{~cm}$ of diameter culture dishes. The day after, cells were treated for $24 \mathrm{~h}$ with $0.34 \mathrm{mM} \mathrm{Fe}(\mathrm{III})$ citrate (Sigma Aldrich), $20 \mu \mathrm{M}$ human Holo-transferrin (Sigma Aldrich) or $1 \mu \mathrm{M} \mathrm{H}-50$ or $1 \mu \mathrm{M} \mathrm{H}-350$. For the experiment, cells were grown in RPMI medium (Lonza). At the end of the incubation, the medium was removed and the cells were washed three times with PBS. Then, they were treated with a non-enzymatic dissociation solution (Sigma Aldrich) for $15 \mathrm{~min}$ at $37^{\circ} \mathrm{C}$, transferred in $15 \mathrm{ml}$ falcon tubes and counted in PBS. Cell number was determined using a cell sorting chamber (Burker-Turk chamber). The cells were divided in falcon tubes containing $1 \times 10^{6}$ cells for each one.

All samples were centrifuged (1100 rpm for 5'), the PBS was removed, and the cells were further washed with PBS and centrifuged (1100 rpm for 5'). All the samples were incubated in $10 \% \operatorname{FBS}(0.5 \mathrm{ml})$ for $30^{\prime}$ at $4^{\circ} \mathrm{C}$, spun down (1100 rpm for 5') and washed twice with PBS $(3 \mathrm{ml})$. The PE conjugated antibody (mAb anti human CD71, BD Pharmingen) selective for TfR1 was added to the samples previously described ( $20 \mu \mathrm{l}$ in $100 \mathrm{ul}$ of $0.1 \%$ BSA/PBS) and to a non-treated sample of Hela cells. As a negative control, a mouse isotype control antibody PEconjugated (Miltenyi Biotec) (5 ul in $100 \mu \mathrm{l}$ of $0.1 \% \mathrm{BSA} /$ PBS) was incubated to a non-treated sample of Hela cells. The incubation was performed at $4^{\circ} \mathrm{C}$ for $40^{\prime}$. All samples were washed with PBS $(2 \times 3 \mathrm{ml})$ and centrifuged $(1100$ rpm for 5'). Finally, cells were diluted in PBS $(250 \mu \mathrm{l})$ and evaluated for their PE fluorescence on a flow cytometer (Becton Dickinson, FACS Calibur). Their PE fluorescence was analyzed using the CELLQUEST PRO program: the mean fluorescence intensity of the treated samples has been calculated as a percentage with respect to the nontreated Hela cells.

\section{MTT assay}

MTT assay is based on the tetrazolium salts reduction to formazan by mitochondrial succinate dehydrogenase (SDH), which is quantified spectrophotometrically. $5 \times 10^{3}$ Hela cells were seeded in a 96-well microtiter plate at $37^{\circ} \mathrm{C}$ and $5 \% \mathrm{CO}_{2}$ air atmosphere. $24 \mathrm{~h}$ later, the cells were incubated for $24 \mathrm{~h}$ at $37^{\circ} \mathrm{C}$ and $5 \% \mathrm{CO}_{2}$ with increasing concentration of $\mathrm{H}-50$, $\mathrm{H}-350$, HoS-50, HoS-350 and $\mathrm{HoS}-1000$ and $\mathrm{H}-$ and HoS-apoferritin. Furthermore, H-350 $(0.5 \mu \mathrm{M})$ and HoS-
$1000(2.5 \mu \mathrm{M})$ were also incubated in absence or in the presence of DFO mesylate $(150 \mu \mathrm{M})$ or chloroquine $(100$ $\mu \mathrm{M})$ for $24 \mathrm{~h}$. After this time, the medium was removed and $100 \mu 1$ of Thiazolyl Blue Tetrazolium Bromide dissolved in medium at the concentration of $0.45 \mathrm{mg} / \mathrm{mL}$ was added into each well and the plate was incubated for $4 \mathrm{~h}$ at $37^{\circ} \mathrm{C}$ and $5 \% \mathrm{CO}_{2}$. Then, the medium was removed, $150 \mu 1$ of DMSO were added into each well to solubilize the formazan salt crystals produced by the metabolism of live cells and the microplate was incubated at room temperature for 30 minutes. Finally, absorbance was read at $570 \mathrm{~nm}$ with iMark microplate reader (Biorad). Cell viability was reported as percentage of death cells observed in treated samples relative to that observed in control cells. The experiment was performed in triplicate and the data were graphically presented as mean \pm SD.

\section{Iron(II) mobilization from $\mathrm{H}$ - and $\mathrm{HoS}$ - ferritin}

Iron loaded $\mathrm{H}$ - and HoS- ferritin $(0.4 \mu \mathrm{M})$ have been incubated up to $3 \mathrm{~h}$ at $25^{\circ} \mathrm{C}$ in different buffers (Hepes/ $\mathrm{NaCl} \mathrm{pH} \mathrm{7.4;0.1} \mathrm{M} \mathrm{acetate} \mathrm{buffer} \mathrm{pH} 5$ ) in the presence of $1 \mathrm{mM}$ 2,2'-bipyridine under aerobic conditions. Incubations of proteins in Hepes $/ \mathrm{NaCl}$ buffer at $\mathrm{pH}=$ 7.4 have been repeated in the presence of glutathione $(0.25 \mathrm{mM})$ or ascorbate $(0.25 \mathrm{mM})$ and of $1 \mathrm{mM}$ $2,2^{\prime}$-bipyridine. The concentration of the reductively mobilized iron cations from ferritin was measured by following the absorption of the Fe(II)-bipyridine complex at $530 \mathrm{~nm}\left(\varepsilon=8650 \mathrm{M}^{-1} \mathrm{~cm}^{-1}\right)$.

\section{Iron(III) mobilization from $\mathrm{H}-$ and $\mathrm{HoS}-$ ferritin}

Iron loaded $\mathrm{H}$ - and HoS- ferritin $(0.4 \mu \mathrm{M})$ have been incubated up to $3 \mathrm{~h}$ at $25^{\circ} \mathrm{C}$ in different buffers (Hepes $/ \mathrm{NaCl} \mathrm{pH} 7.4 ; 0.1 \mathrm{M}$ acetate buffer $\mathrm{pH}$ 5) in the presence of $0.25 \mathrm{mM}$ xylenol orange (Sigma) under aerobic conditions. At different time intervals the solutions have been centrifuged by vivaspin filters $(50000 \mathrm{MW}$ cut-off) (Sartorius) and $100 \mu \mathrm{l}$ of the filtered solutions were taken to measure $\mathrm{Fe}(\mathrm{III})$ concentration after adding $700 \mu \mathrm{l}$ of xylenol orange $0.25 \mathrm{mM}$ in $20 \mathrm{mM} \mathrm{H}_{2} \mathrm{SO}_{4}$. The $100 \mu \mathrm{l}$ taken were renewed at each time interval. The concentration of $\mathrm{Fe}$ (III) released from ferritin was measured by following the absorption of the Fe(III)xylenol orange complex at $560 \mathrm{~nm}\left(\varepsilon=1647 \mathrm{M}^{-1} \mathrm{~cm}^{-1}\right)$.

\section{Transmission electron microscopy (TEM) studies}

TEM analysis of $\mathrm{H}-350, \mathrm{HoS}-350$ and $\mathrm{HoS}-1000$ samples $(10 \mu \mathrm{M}$ in Hepes/ $\mathrm{NaCl} \mathrm{pH}$ 7.4) was carried out using a JEOL JEM-3010, a $300 \mathrm{kV}$ ultrahigh resolution analytical Theoretical resolution of $0.17 \mathrm{~nm}$. Electron gun: Cool beam LaB6 Equipped with a Gatan US1000 CCD camera. 
TEM analysis of HeLa cells was carried out after their incubation for $3 \mathrm{~h}$ at $37^{\circ} \mathrm{C}$ with $\mathrm{H}-3501 \mu \mathrm{M}$ or HoS-1000 2.5 $\mu \mathrm{M}$. Control cells were incubated under the same conditions without ferritin addition. Cells were fixed with $2.5 \%$ glutaraldehyde solution in $0.1 \mathrm{M}$ phosphate buffer $\mathrm{pH} 7.4$ and post-fixed in osmium tetroxide solution. Samples were then dehydrated in graded alcohol and embedded under vacuum in Epson $812.70 \mathrm{~nm}$ slices were sequentially stained with $0.04 \%$ bismuth subnitrate, saturated uranyl acetate and $0.25 \%$ lead citrate and viewed with a Jeol 1400 microscopy (USA). The latter staining procedure enhances ferritin detection [36].

\section{Measurement of reactive oxygen species (ROS) production}

Intracellular ROS production was detected using the non-fluorescent cell permeating compound, 2',7'-dichlorodihydro-fluorescein diacetate (DCF-DA). In order to evaluate the effect of $\mathrm{H}$ - and HoS-ferritin on the ROS production, Hela cells were seeded at a density of $1 \times 10^{5}$ cells in $3.5 \mathrm{~cm}$ - diameter dishes and were placed for $24 \mathrm{~h}$ in a wet $\left(37^{\circ} \mathrm{C}\right) 5 \% \mathrm{CO}_{2}$ air atmosphere incubator. Iron-loaded $\mathrm{H}$ - and $\mathrm{HoS}$-ferritins and $\mathrm{H}$ - and HoS-apoferritins were incubated at protein concentration of $5 \mu \mathrm{M}$ for $24 \mathrm{~h}$ at $37^{\circ} \mathrm{C}, 5 \% \mathrm{CO}_{2}$. After the incubation, cells were washed two times with $\mathrm{PBS}$ and incubated with $5 \mu \mathrm{M}$ of DCF-DA for $30^{\prime}$ at $37^{\circ} \mathrm{C}, 5 \% \mathrm{CO}_{2}$ in prewarmed EBSS buffer. Cells were then washed two times with PBS and detached using a cell scraper in 100ul of PBS. Cells were sonicated in ice for $5 \mathrm{sec}$ at $30 \%$ power and the protein content of cells were determined by the commercial Bradford method. The fluorescence of cells lysates was measured using a fluorometer microplate reader Promega Glomax-multi detection system (Promega Corporation, 2800 Woods Hollow Road Madison, WI 53711 USA) using a blue module (ex 490 nm, em 510-570 $\mathrm{nm}$ ) on samples containing $10 \mu \mathrm{g}$ of cell proteins in $200 \mu \mathrm{l}$ of PBS. The fluorescence intensity of iron loaded $\mathrm{H}^{-}$and HoS - ferritins and $\mathrm{H}-$ and $\mathrm{HoS}-$ apoferritins cells lysates samples was calculated as a percentage with respect to the fluorescence intensity values of untreated cells used as a control.

\section{ACKNOWLEDGMENTS}

This research was performed in the framework of the Consorzio Interuniversitario di Ricerca in Chimica dei Metalli dei Sistemi Biologici (CIRCMSB) and of the Consorzio Interuniversitario Risonanze Magnetiche di Metallo Proteine (CIRMMP).

\section{CONFLICTS OF INTEREST}

All authors declare no conflicts of interest.

\section{GRANT SUPPORT}

This research was funded by MIUR (PRIN 2012 code 2012SK7ASN). SA and SGC acknowledge the European Union's Horizon 2020 research and innovation programme under grant agreement No 668119 (project "IDentIFY"), SC the postdoctoral grant by Fondazione Cassa di Risparmio di Firenze ( $\left.n^{\circ} 2013.0494\right)$ provided by FiorGen.

\section{REFERENCES}

1. Liu X, Theil EC. Ferritins: dynamic management of biological iron and oxygen chemistry. Acc Chem Res. 2005; 38:167-75.

2. Theil EC, Behera RK, Tosha T. Ferritins for chemistry and for life. Coord Chem Rev. 2013; 257:579-586.

3. Finazzi D, Arosio P. Biology of ferritin in mammals: an update on iron storage, oxidative damage and neurodegeneration. Arch Toxicol. 2014; 88:1787-802.

4. Pozzi C, Di Pisa F, Bernacchioni C, Ciambellotti S, Turano $\mathrm{P}$, Mangani S. Iron binding to human heavy-chain ferritin. Acta Crystallogr D Biol Crystallogr 2015; 71:1909-1920.

5. Santambrogio P, Levi S, Cozzi A, Corsi B, Arosio P. Evidence that the specificity of iron incorporation into homopolymers of human ferritin L- and H-chains is conferred by the nucleation and ferroxidase centres. Biochem J. 1996; 314:139-144.

6. Liang M, Fan K, Zhou M, Duan D, Zheng J, Yang D, Feng J, Yan X. H-ferritin-nanocaged doxorubicin nanoparticles specifically target and kill tumors with a single-dose injection. Proc Natl Acad Sci U S A. 2014; 111:14900-14905.

7. Cutrin JC, Geninatti Crich S, Burghelea D, Dastrù W, Aime S. Curcumin/Gd loaded apoferritin: a novel "theranostic" agent to prevent hepatocellular damage in toxic induced acute hepatitis. Mol Pharm. 2013; 10:2079-2085.

8. Pontillo N, Pane F, Messori L, Amoresano A, Merlino A. Cisplatin encapsulation within a ferritin nanocage: a highresolution crystallographic study. Chem Commun (Camb). 2016; 52:4136-39.

9. Dominguez-Vera JM. Iron(III) complexation of Desferrioxamine B encapsulated in apoferritin. J Inorg Biochem. 2004; 98:469-472.

10. Li JY, Paragas N, Ned RM, Qiu A, Viltard M, Leete T, Drexler IR, Chen X, Sanna-Cherchi S, Mohammed F, Williams D, Lin CS, Schmidt-Ott KM, et al. Scara5 is a ferritin receptor mediating non-transferrin iron delivery. Dev Cell. 2009; 16:35-46.

11. Li L, Fang CJ, Ryan JC, Niemi EC, Lebrón JA, Björkman PJ, Arase H, Torti FM, Torti SV, Nakamura MC, Seaman WE. Binding and uptake of $\mathrm{H}$-ferritin are mediated by human transferrin receptor-1. Proc Natl Acad Sci U S A. 2010; 107:3505-3510. 
12. Richardson DR, Ponka P. The molecular mechanisms of the metabolism and transport of iron in normal and neoplastic cells. Biochim Biophys Acta. 1997; 1331:1-40.

13. Lui GY, Kovacevic Z, Richardson V, Merlot AM, Kalinowski DS, Richardson DR. Targeting cancer by binding iron: Dissecting cellular signaling pathways. Oncotarget. 2015; 6:18748-79. https://doi.org/10.18632/oncotarget.4349.

14. Habel ME, Jung D. cMyc overexpression in Ramos Burkitt's lymphoma cell line predispose to iron homeostasis disruption in vitro. Biochem Biophys Res Commun. 2006; 341:1309-16.

15. Yang WS, Stockwell BR. Synthetic lethal screening identifies compounds activating iron-dependent, nonapoptotic cell death in oncogenic-RAS-harboring cancer cells. Chem Biol. 2008; 15:234-45.

16. Jutz G, van Rijn P, Santos Miranda B, Böker A. Ferritin: a versatile building block for bionanotechnology. Chem Rev. 2015; 115:1653-701.

17. Plath LD, Ozdemir A, Aksenov AA, Bier ME. Determination of iron content and dispersity of intact ferritin by superconducting tunnel junction cryodetection mass spectrometry. Anal Chem. 2015; 87:8985-8993.

18. Ravera E, Ciambellotti S, Cerofolini L, Martelli T, Kozyreva T, Bernacchioni C, Giuntini S, Fragai M, Turano P, Luchinat C. Solid-state NMR of PEGylated proteins. Angew Chem Int Ed Engl. 2016; 55:2446-49.

19. Ward JH, Kushner JP, Kaplan J. Regulation of HeLa cell transferrin receptors. J Biol Chem. 1982; 257:10317-23.

20. Zhang DL, Ghosh MC, Rouault TA. The physiological functions of iron regulatory proteins in iron homeostasis an update. Front Pharmacol. 2014; 5:124.

21. Iancu TC. Ultrastructural aspects of iron storage, transport and metabolism. J Neural Transm (Vienna). 2011; 118:329-335.

22. Maxfield FR, Yamashiro DJ. Endosome acidification and the pathways of receptor-mediated endocytosis. Adv Exp Med Biol. 1987; 225:189-198.

23. Huotari J, Helenius A. Endosome maturation. EMBO J. 2011; 30:3481-3500.

24. Gay C, Collins J, Gebicki JM. Determination of iron in solutions with the ferric-xylenol orange complex. Anal Biochem. 1999; 273:143-48.

25. Eid R, Arab NT, Greenwood MT. Iron mediated toxicity and programmed cell death: A review and a re-examination of existing paradigms. Biochim Biophys Acta. 2017; 1864:399-430.
26. Conti L, Lanzardo S, Ruiu R, Cadenazzi M, Cavallo F, Aime S, Geninatti Crich S. L-Ferritin targets breast cancer stem cells and delivers therapeutic and imaging agents. Oncotarget. 2016; 7:66713-27. https://doi.org/10.18632/oncotarget.10920.

27. Geninatti Crich S, Cadenazzi M, Lanzardo S, Conti L, Ruiu R, Alberti D, Cavallo F, Cutrin JC, Aime S. Targeting ferritin receptors for the selective delivery of imaging and therapeutic agents to breast cancer cells. Nanoscale. 2015; 7:6527-6533.

28. López-Castro JD, Delgado JJ, Perez-Omil JA, Gálvez N, Cuesta R, Watt RK, Domínguez-Vera JM. A new approach to the ferritin iron core growth: influence of the $\mathrm{H} / \mathrm{L}$ ratio on the core shape. Dalton Trans. 2012; 41:1320-1324.

29. Bernacchioni C, Pozzi C, Di Pisa F, Mangani S, Turano P. Ferroxidse activity in eukaryotic ferritin is controlled by accessory iron binding sites in the catalytic cavity. Chemistry. 2016; 22:16213-16219.

30. Behera RK, Theil EC. Moving Fe2+ from ferritin ion channels to catalytic $\mathrm{OH}$ centers depends on conserved protein cage carboxylates. Proc Natl Acad Sci U S A. 2014; 111:7925-30.

31. Pozzi C, Ciambellotti S, Bernacchioni C, Di Pisa F, Mangani S, Turano P. Chemistry at the protein-mineral interface in L-ferritin assists the assembly of a functional ( $\mu 3$-oxo)Tris $[(\mu 2$-peroxo)] triiron(III) cluster. Proc Natl Acad Sci USA. 2017; 114:2580-85.

32. Zhao G, Arosio P, Chasteen ND. Iron(II) and hydrogen peroxide detoxification by human $\mathrm{H}$-chain ferritin. An EPR spin-trapping study. Biochemistry. 2006; 45:3429-36.

33. Theil E, Turano P, Mangani S. Time lapse, anomalous X-ray diffraction shows how $\mathrm{Fe} 2+$ substrate ions move throgh ferritin protein nanocages to oxidoreductase sites. Acta Crystallogr D Biol Crystallogr. 2015; D71:941-953.

34. De Domenico I, Vaughn MB, Li L, Bagley D, Musci G, Ward DM, Kaplan J. Ferroportin-mediated mobilization of ferritin iron precedes ferritin degradation by the proteasome. EMBO J. 2006; 25:5396-5404.

35. Ferrante G, Sykora S. Technical aspects of fast field cycling. Adv Inorg Chem. 2005; 57:405-70.

36. Ainsworth SK, Karnovsky MJ. An ultrastructural staining method for enhancing the size and electron opacity of ferritin in thin sections. J Histochem Cytochem. 1972; 20:225-229. 